SHORT REPORT

\title{
Injury patterns in children with frequent emergency department visits
}

\section{B Laursen}

Emerg Med J 2006;23:59-60. doi: 10.1136/emj.2004.021469

Objectives: To compare injury patterns in children with many and few emergency department (ED) visits in order to reveal the causes for the frequent visits.

Methods: Three cohorts of Danish children (total 579721 children) were followed for three years when their ages were $0-2,6-8$, and 12-14 years. Information on all ED visits was obtained from the Danish National Patient Registry. Injury type, place of accident, injury mechanism, admission, and distance to ED were compared between children with frequent ED visits (five or more during the three years) and children with only one visit.

Results: Children with frequent visits had a different injury pattern with $0-46 \%$ more superficial injuries and 25-82\% more dislocations, sprains, and strains. There was $20-30 \%$ fewer fractures and 12\% fewer falls from a higher level. 15$51 \%$ fewer were admitted.

Conclusions: Children with many ED visits had less severe injuries and more dislocations, sprains, and strains.

$\mathrm{R}$ isk of injuries in children depends on many traditionally measured factors-for example, age, sex, ethnicity, and socio-economic factors. ${ }^{1}$ These may be related to specific risk factors-for example, environmental, living in surroundings with a higher risk of burns, corrosions, and poisonings or more dangerous traffic - or personal risk factors-for example, performing more sports. As children exposed to increased risks may be frequent visitors at emergency departments (EDs), analysing hospital registrations may reveal the injury patterns and accident characteristics. Such a long term analysis was possible because all ED visits in Denmark since 1995 have been recorded at the individual level in the National Patient Registry. The purpose of the present study was therefore to determine differences in the type of accidents and injuries between children with many and few ED visits in order to reveal the causes for the frequent visits.

\section{METHODS}

From all children living in Denmark, three independent cohorts of children were constructed based on year of birth, each followed for a period of three years when their ages were $0-2,6-8$, and $12-14$ years. In total, the three cohorts included 579721 children.

Taken from the National Patient Registry in Denmark, all primary ED visits related to unintentional injuries were included based on the hospital registration of reason for contact. Each record comprised personal identification number and information on diagnosis (ICD-10), mechanism of injury, activity when the injury occurred, and place of the accident. The total number of visits during the three year period was used for classifying the children into three groups with one ED visit ("once" group), 2-4 visits, and five or more ED visits ("frequent" group). For each of these groups, admission, place of accident, mechanism, diagnosis, and ED distance were analysed. Diagnoses (ICD-10) were categorised as superficial injury, open wounds, fractures, dislocation/ sprain/strain, burn/corrosion, poisoning, other. Distance from the municipality to the nearest ED was classified into $<10 \mathrm{~km}, 10-19 \mathrm{~km}$, and $\geqslant 20 \mathrm{~km}$.

\section{Statistics}

Because only between 1.1 and $4.2 \%$ of the children went into and out of the cohorts, each cohort was treated as if it consisted of a constant population during the period. Differences between the groups were tested using $\chi^{2}$ test, with each emergency visit as the fundamental unit. Cluster effects because of the repeated visits for each child were not corrected for as the intracluster correlation in most cases was below 0.1. Significance was assumed for $\mathrm{p}<0.05$.

\section{RESULTS}

A total of $265244 \mathrm{ED}$ visits related to unintentional injuries were recorded with 182917 children involved. This resulted in an ED visit incidence of $15.3 \%$ per year. Altogether, $396804(68.4 \%)$ of the children had no ED visits during the period, $128825(22.2 \%)$ had one visit, 51615 (8.9\%) had 2-4 visits, and $2477(0.4 \%)$ had five or more visits (accounting for $5.5 \%$ of the visits). In the "frequent" group there were between 18-31 times more children than expected from a Poisson distribution with equal ED visit probability for all children. The relative magnitude of the "frequent" group increased with age from $220(0.1 \%)$ of the $0-2$ years old children to $1852(1.1 \%)$ of the $12-14$ years old.

Table 1 shows the occurrences of different injury characteristics in the "frequent" group compared with the "once" group-for example, for the 12-14 years old children, $2.5 \%$ of the ED visits resulted in admissions in the "frequent group" compared with $4.3 \%$ in the "once group" resulting in a ratio of 0.58. Despite this, more children were admitted in the "frequent" group—0.155 admissions per child compared with 0.043 admissions in the "once" group.

\section{DISCUSSION}

The present study showed that $0.4 \%$ of the children had five or more ED visits during the three year period. The places of accidents were almost the same for the "frequent" and "once" groups. This does not point to any particular environmental risk for the children in the "frequent" group and it does not show effects of an eventual lack of safety precautions in the home, as this could result in more injuries in residential areas. The "frequent" group had less injury severity compared with the "once" group: they had more superficial injuries and fewer were admitted to hospital. In contrast, dislocation, sprain, and strain injuries were over represented in the "frequent" group, which indicates a group of children that are susceptible to these injuries possibly because of individual characteristics such as anatomical

Abbreviations: ED, emergency department 


\begin{tabular}{|c|c|c|c|c|}
\hline Age (years) & & $0-2$ & $6-8$ & $12-14$ \\
\hline Admission & & $0.85 \mathrm{Cl} 0.62-1.12$ & $0.49 \mathrm{Cl} 0.38-0.63$ & $0.58 \mathrm{Cl} 0.51-0.65$ \\
\hline & & $1.17 \mathrm{Cl} 1.12-1.22$ & $0.95 \mathrm{Cl} 0.92-0.99$ & $0.85 \mathrm{Cl} 0.83-0.87$ \\
\hline Distance & $<10 \mathrm{~km}$ & 1.23 Cl $1.19-1.26$ & $1.22 \mathrm{Cl} 1.19-1.24$ & 1.21 Cl $1.20-1.23$ \\
\hline \multirow[t]{4}{*}{ Mechanism } & Fall from higher level & 0.89 Cl $0.80-0.99$ & 0.89 Cl 0.82-0.97 & $0.88 \mathrm{Cl} 0.84-0.93$ \\
\hline & Fall, other & $1.00 \mathrm{Cl} 0.89-1.13$ & $1.08 \mathrm{Cl} 1.00-1.17$ & $0.96 \mathrm{Cl} 0.93-0.99$ \\
\hline & Contact & $1.12 \mathrm{Cl} 1.01-1.23$ & $1.10 \mathrm{Cl} 1.04-1.16$ & $1.13 \mathrm{Cl} 1.11-1.16$ \\
\hline & Acute overexertion & $1.92 \mathrm{Cl} 1.57-2.32$ & $1.74 \mathrm{Cl} 1.49-2.01$ & 1.26 Cl $1.20-1.33$ \\
\hline \multirow[t]{4}{*}{ Place } & Transport area & 0.91 Cl $0.68-1.19$ & $1.01 \mathrm{Cl} 0.88-1.14$ & $0.81 \mathrm{Cl} 0.77-0.86$ \\
\hline & Residential area & $1.03 \mathrm{Cl} 1.00-1.06$ & $1.01 \mathrm{Cl} 0.96-1.06$ & $1.07 \mathrm{Cl} 1.03-1.10$ \\
\hline & Institution, school & 0.81 Cl $0.67-0.97$ & $1.00 \mathrm{Cl} 0.94-1.06$ & $1.03 \mathrm{Cl} 1.00-1.07$ \\
\hline & Sports area & Too few & $1.21 \mathrm{Cl} 1.05-1.39$ & $1.10 \mathrm{Cl} 1.07-1.14$ \\
\hline \multirow[t]{6}{*}{ Injury } & Superficial & $0.98 \mathrm{Cl} 0.89-1.08$ & $1.46 \mathrm{Cl} 1.38-1.53$ & $1.33 \mathrm{Cl} 1.30-1.36$ \\
\hline & Open wound & 0.86 Cl $0.78-0.94$ & 0.56 Cl $0.51-0.62$ & $0.45 \mathrm{Cl} 0.42-0.48$ \\
\hline & Fracture & 0.80 Cl $0.64-0.99$ & 0.79 Cl $0.71-0.87$ & $0.70 \mathrm{Cl} 0.67-0.73$ \\
\hline & $\begin{array}{l}\text { Dislocation, sprain, } \\
\text { and strain }\end{array}$ & $1.82 \mathrm{Cl} 1.57-2.10$ & $1.59 \mathrm{Cl} 1.45-1.74$ & $1.25 \mathrm{Cl} 1.21-1.28$ \\
\hline & Burn, corrosion & 0.69 Cl $0.50-0.92$ & $0.70 \mathrm{Cl} 0.39-1.15$ & $0.80 \mathrm{Cl} 0.63-1.00$ \\
\hline & Poisoning & $1.17 \mathrm{Cl} 0.76-1.72$ & 0.59 Cl $0.27-1.11$ & $0.49 \mathrm{Cl} 0.28-0.80$ \\
\hline
\end{tabular}

alignment, muscle strength and reaction time, and postural sway. ${ }^{2}$

There were more "frequent" visits among children living close to the ED in all age groups. It has previously been shown that distance is of importance when injuries occur in school children but not for pre-school children. ${ }^{3}$ Other factors of importance are availability of general practitioner services. ${ }^{4}$ These factors have not been assessed in the present study but may be of importance since some EDs required a referral.

The National Patient Registry collects data for administrative purposes and not for research; therefore, the quality of data may differ among hospitals. A validation study had estimated the quality of the codes and for the accident codes between $85-98 \%$ has been found to be correct. ${ }^{5}$

\section{ACKNOWLEDGEMENTS}

The present study was supported by the Danish Research Agency, the Health Insurance Foundation, "Foreningen Østifterne", and "Egmont Fonden".

Competing interests: none declared.

As a pure register study, it needed no approval from the ethics committee.

The Corresponding Author has the right to grant on behalf of all authors and does grant on behalf of all authors, an exclusive licence (or non-exclusive for government employees) on a worldwide basis to the BMJ Publishing Group Ltd and its Licensees to permit this article (if accepted) to be published in EMJ editions and any other BMJPG Ltd products to exploit all subsidiary rights, as set out in our licence (http:// emj.bmijournals.com/misc/ifora/licenceform.shtml)

Correspondence to: B Laursen, National Institute of Public Health, Denmark, Øster Farimagsgade 5, DK-1399 Copenhagen K, Denmark; bla@niph.dk

Received 17 October 2004

In revised form 21 January 2005

Accepted for publication 27 February 2005

\section{REFERENCES}

1 Engstrom K, Diderichsen F, LaFlamme L. Socioeconomic differences in injury risks in childhood and adolescence: a nation-wide study of intentional and unintentional injuries in Sweden. Inj Prev 2002;8:137-42.

2 Beynnon BD, Murphy DF, Alosa DM. Predictive factors for lateral ankle sprains: a literature review. J Athl Train 2002;37:376-80.

3 Ahlamaa-Tuompo J, Linna M. The socio-economic and demographic context of children's emergency injury visits in Helsinki in 1991-1994. Eur J Emerg Med 1998;5:429-40.

4 Lewis $\mathrm{H}$. Accident and emergency department utilisation: a consumer survey. N Z Med J 1988;101:486-7.

5 Mosbech J, Jorgensen J, Madsen $M$, et al. The national patient registry. Evaluation of data quality. Ugeskr Laeger 1995;157:3741-5. 